\title{
Review:
}

\section{Transcriptional snapshots provide insights into the molecular basis of arbuscular mycorrhiza in the model legume Medicago truncatula}

\author{
Natalija Hohnjec $^{\mathrm{A}, \mathrm{B}}$, Kolja Henckel ${ }^{\mathrm{C}}$, Thomas Bekel ${ }^{\mathrm{C}}$, Jerome Gouzy ${ }^{\mathrm{D}}$, Michael Dondrup ${ }^{\mathrm{B}, \mathrm{C}}$, \\ Alexander Goesmann ${ }^{\mathrm{C}}$ and Helge Küster ${ }^{\mathrm{A}, \mathrm{B}, \mathrm{E}}$ \\ ${ }^{\mathrm{A}}$ Institute for Genome Research, Center for Biotechnology (CeBiTec), Bielefeld University, \\ D-33594 Bielefeld, Germany. \\ ${ }^{B}$ International Graduate School in Bioinformatics and Genome Research, Center for Biotechnology (CeBiTec), \\ Bielefeld University, D-33594 Bielefeld, Germany. \\ ${ }^{\mathrm{C}}$ Bioinformatics Resource Facility, Center for Biotechnology (CeBiTec), Bielefeld University, \\ D-33594 Bielefeld, Germany. \\ ${ }^{\mathrm{D}}$ Laboratoire des Interactions Plantes Micro-organismes LIPM, Chemin de Borde-Rouge-Auzeville, \\ BP 52627, 31326 Castanet Tolosan, Cedex, France. \\ ${ }^{\mathrm{E}}$ Corresponding author. Email: Helge.Kuester@Genetik.Uni-Bielefeld.DE
}

This paper originates from a presentation at the Third International Conference on Legume Genomics and Genetics, Brisbane, Queensland, Australia, April 2006.

\begin{abstract}
The arbuscular mycorrhizal (AM) association between terrestrial plants and soil fungi of the phylum Glomeromycota is the most widespread beneficial plant-microbe interaction on earth. In the course of the symbiosis, fungal hyphae colonise plant roots and supply limiting nutrients, in particular phosphorus, in exchange for carbon compounds. Owing to the obligate biotrophy of mycorrhizal fungi and the lack of genetic systems to study them, targeted molecular studies on AM symbioses proved to be difficult. With the emergence of plant genomics and the selection of suitable models, an application of untargeted expression profiling experiments became possible. In the model legume Medicago truncatula, high-throughput expressed sequence tag (EST)-sequencing in conjunction with in silico and experimental transcriptome profiling provided transcriptional snapshots that together defined the global genetic program activated during AM. Owing to an asynchronous development of the symbiosis, several hundred genes found to be activated during the symbiosis cannot be easily correlated with symbiotic structures, but the expression of selected genes has been extended to the cellular level to correlate gene expression with specific stages of AM development. These approaches identified marker genes for the AM symbiosis and provided the first insights into the molecular basis of gene expression regulation during AM.
\end{abstract}

Keywords: arbuscule-specific genes, EST-sequencing, expression databases, Glomus spp., in silico transcriptome profiling, microarray-based transcriptome profiling, TIGR M. truncatula Gene Index.

\section{Introduction}

Some $80 \%$ of all terrestrial plants enter an arbuscular mycorrhiza (AM) endosymbiosis with fungi of the phylum Glomeromycota (Smith and Read 1997; Schüssler et al. 2001). During AM, fungal hyphae from an extraradical mycelium penetrate the root epidermis through an appressorium, pass through the outer cortical cell layers and subsequently proliferate in the inner cortex (Harrison 1997, 2005; Genre et al. 2005). In the 'Arum' type of fungal colonisation, these intraradical, intercellular hyphae terminate in highly branched, intracellular structures called arbuscules (Bonfante and Perotto 1995), whereas in the

Abbreviations used: AM, arbuscular mycorrhiza; bcp, blue-copper-binding protein; EST, expressed sequence tag; ET, expressed transcript; GPI, glycosylphosphatidylinositol; SAMS, sequence analysis and management system; SSH, suppressive-subtractive hybridisation; SteN, statistical electronic northern blot; TC, tentative consensus. 
'Paris' type, little or no arbuscule development is observed (Smith and Read 1997).

Arbuscular mycorrhiza interactions are characterised by the bidirectional exchange of nutrients. In return for carbohydrates, fungal microsymbionts transfer minerals, in particular phosphorus, to the plant (Shachar-Hill et al. 1995; Smith et al. 2001). In the well-studied 'Arum'-type interactions, the uptake of phosphorus and minerals occurs at the peri-arbuscular interface, which encompasses the fungal arbuscular membrane, the periarbuscular matrix, and the plant periarbuscular membrane (Gianinazzi-Pearson 1996; Harrison 1999; Parniske 2000). It has been shown that the uptake of phosphorus is energy-dependent, with plant and fungal plasma membrane $\mathrm{H}^{+}$-ATPases as well as a plant phosphate transporter being exclusively localised at the arbuscular interface (Gianinazzi-Pearson et al. 2000; Ferrol et al. 2002; Harrison et al. 2002; Requena et al. 2003). In contrast to the nutrient uptake by the plant, intraradical hyphae are thought to be responsible for the translocation of carbohydrates to the fungus (Bago et al. 2000; Graham and Miller 2005).

Molecular research on AM suffers from two major obstacles: (1) an asynchronous development of the symbioses leading to the concomitant presence of different stages of AM in root systems and (2) the obligate biotrophy of AM fungi. Consequently, molecular information obtained some years ago on genes expressed during AM interactions was limited, and only a few mycorrhiza-induced genes had been reported in different species (Franken and Requena 2001; GianinazziPearson and Brechenmacher 2004).

With the emergence of plant genomics, the identification of a more comprehensive collection of genes activated during AM became possible. In recent years, expression profiling strategies comprising high-throughput EST-sequencing, in silico profiling, and global microarray-based transcriptome profiling were pursued to specify genes activated during mycorrhizal interactions. These transcriptomics approaches benefited from the identification of two model plants from the legume family that proved to be excellent models also for AM, Medicago truncatula (Barker et al. 1990) and Lotus japonicus (Handberg and Stougaard 1992). In addition to well advanced genome sequencing projects and the existence of comprehensive mutant collections (Tadege et al. 2005; Udvardi et al. 2005; Young et al. 2005; Sato and Tabata 2006; Town 2006), more than 330000 ESTs were generated in the two legumes (Quackenbush et al. 2001), and several expression profiling tools have been developed (Colebatch et al. 2002, 2004; Kouchi et al. 2004; Küster et al. 2004; Hohnjec et al. 2005; Lohar et al. 2006).

An important benefit of selecting legumes as AM models derives from the fact that this genus is able to enter a second wide-spread plant-microbe symbiosis leading to the development of nitrogen-fixing root nodules (Brewin 1991; Vessey et al. 2005). Based on the existence of common signalling cascades during the early stages of nodulation and mycorrhization (Limpens and Bisseling 2003; Geurts et al. 2005; Stacey et al. 2006), it is speculated that the comparably young root nodule symbiosis adopted and modified much more ancient signal transduction pathways leading to AM formation (Gianinazzi-Pearson and Dénarié 1997), placing AM research in a general context of molecular research on plant-microbe signalling. Studies on legume mutants defective in early responses to nodulating rhizobia or mycorrhizal fungi (Cullimore and Dénarié 2003; Kistner et al. 2005) have recently delivered a detailed molecular understanding of the early infection events leading to nodulation and mycorrhization (Kistner and Parniske 2002). Interestingly, fungal recognition is proposed to require the presence of a Myc-factor that, similar to the action of Nodfactors triggering nodulation, is able to initiate AM formation (Kosuta et al. 2003).

Complementing the genomics activities in legume macrosymbionts, a genome project has recently been launched for the AM fungus Glomus intraradices. This model fungus is characterised by a haploid and comparably small genome of only $\sim 15 \mathrm{Mb}$ (Hijri and Sanders 2004) containing only few repetitive sequences (Lammers et al. 2004; Martin et al. 2004). The availability of full genome sequences of two model legumes and a model fungus can be expected to further advance our understanding of AM symbioses in the forthcoming years, although the lack of a transformation system for mycorrhizal fungi remains a major drawback. At the dawn of the whole-genome era of AM research, we summarise here recent advances in the transcriptomics of AM interactions in the model legume $M$. truncatula. These efforts provided a framework of the expressed plant genome during $\mathrm{AM}$ and the transcriptional snapshots obtained, together with forward genetics studies on legume mutants, substantially widened our molecular perspective of the AM symbiosis.

\section{Global approach I: high-throughput EST-sequencing provides an overview of the Medicago truncatula transcriptome in arbuscular mycorrhiza}

Only recently, information on genes expressed during AM interactions was limited (Franken and Requena 2001). In case of the $M$. truncatula-Glomus spp. symbiosis, this situation has improved substantially over the last couple of years owing to the application of untargeted high-throughput EST-sequencing (Gianinazzi-Pearson and Brechenmacher 2004). In the latest release of the TIGR $M$. truncatula Gene Index (http://www.tigr.org/tdb/tgi; verified 16 June 2006; Quackenbush et al. 2001), five comprehensive cDNA libraries representing AM roots are listed (Table 1). These libraries stem from studies exclusively covering the AM transcriptome (MHAM and MHAM2 libraries, Liu et al. 2003; MtAMP library, Frenzel et al. 2005; MtGIM library, Wulf et al. 2003; Frenzel et al. 2005) as well as from a large-scale project targeted at specifying genes expressed 
Table 1. High-throughput EST-sequencing to study the Medicago truncatula AM symbiosis

The following five cDNA-libraries were subjected to untargeted EST-sequencing and have been included in the current release 8 of the TIGR M. truncatula Gene Index (http://www.tigr.org/tdb/tgi; Quackenbush et al. 2001)

\begin{tabular}{|c|c|c|c|c|c|}
\hline Library & Type & ESTs & AM fungus & Library description & Reference \\
\hline MHAM & Random & 7351 & G. versiforme & $\begin{array}{l}\text { Mycorrhizal roots harvested between } 10 \text { and } 38 \mathrm{~d} \\
\text { post inoculation }\end{array}$ & Liu et al. (2003) \\
\hline MHAM2 & Random & 1679 & G. versiforme & $\begin{array}{l}\text { Mycorrhizal roots harvested between } 10 \text { and } 38 \mathrm{~d} \\
\text { post inoculation }\end{array}$ & Liu et al. (2003) \\
\hline $\mathrm{MtBC}$ & Random & 8567 & G. intraradices & $\begin{array}{l}\text { Mycorrhizal roots harvested } 3 \text { weeks post } \\
\text { inoculation }\end{array}$ & Journet et al. (2002) \\
\hline MtAMP & Random & 3448 & G. intraradices & $\begin{array}{l}\text { Mycorrhizal roots harvested } 5 \text { weeks post } \\
\text { inoculation }\end{array}$ & Frenzel et al. (2005) \\
\hline MtGIM & SSH & 1686 & G. intraradices & $\begin{array}{l}\text { Mycorrhizal roots harvested } 3 \text { weeks post } \\
\text { inoculation }\end{array}$ & $\begin{array}{l}\text { Wulf et al. (2003); } \\
\quad \text { Frenzel et al. (2005) }\end{array}$ \\
\hline
\end{tabular}

both during mycorrhization and nodulation (MtBC library, Journet et al. 2002). Whereas the MHAM and MHAM2 libraries contain ESTs from the M. truncatula-G. versiforme interaction, all other libraries represent the AM symbiosis between $M$. truncatula and $G$. intraradices.

Together, 22731 ESTs were generated from the five M. truncatula AM libraries mentioned above, $\sim 10 \%$ of all ESTs generated in this species so far. This makes the M. truncatula / Glomus spp. interaction the best-studied model for AM at the level of EST-sequencing. Since AM roots contain polyadenylated transcripts both from the plant and the mycorrhizal fungus, a certain proportion of the transcript sequences obtained can be expected to be of fungal origin. While bioinformatics approaches to $a b$ initio predict the origin of AM transcript sequences proved to be more error-prone than for other plant-microbe interactions (Hraber and Weller 2001), analyses based on comparisons to ESTs from non-mycorrhizal tissues or to genomic sequences as well as PCR-amplifications from either M. truncatula or Glomus spp. genomic DNA indicated that the proportion of fungal sequences in AM-specific TCs or singleton ESTs was between 6.5 and 9\% (Liu et al. 2003; Hohnjec et al. 2005). This is consistent with the observation that only between 4.5 and $8.1 \%$ of total RNA from AM roots is of fungal origin (Liu et al. 2003). Nevertheless, a definitive proof of the origin of most AM transcript sequences will have to await completion of the M. truncatula or the G. intraradices genome sequences.

\section{Global approach II: in silico profiles predict several hundred Medicago truncatula genes as specifically expressed in arbuscular mycorrhiza}

In the latest release of the TIGR M. truncatula Gene Index, 226923 ESTs are assembled. These were generated from 61 cDNA libraries that, apart from representing curated clone collections, covered $53 \mathrm{M}$. truncatula tissues and growth conditions. Automatic EST-clustering was applied to define 36878 unique sequences, and these were divided into 18612 TCs ('Tentative Consensus' sequences) and
18266 singletons (TIGR MtGI, http://www.tigr.org/tdb/tgi/; Quackenbush et al. 2001).

The origin of ESTs clustered in a particular TC can be used to mine information on the tissue-specific expression of the corresponding gene (Fig. 1), an approach referred to as eNorthern, in silico or digital expression profiling (Alba et al. 2004). In addition to simply scoring EST frequencies, mathematical approaches were developed to associate a test statistic with a predicted differential gene expression (Stekel et al. 2000). Such in silico studies became quite popular in research on root endosymbioses in the last couple of years, and several hundred genes were predicted to be up-regulated during nodulation and mycorrhization (Fedorova et al. 2002; Journet et al. 2002; Manthey et al. 2004; Frenzel et al. 2005; Tesfaye et al. 2006), based on different subsets of ESTs.

With respect to AM formation, no comparable approach was carried out on the basis of the latest, most comprehensive release of the TIGR M. truncatula Gene Index. To specify all M. truncatula TCs exclusively composed of ESTs from AM roots, we developed a SteN ('Statistical electronic Northern Blot') tool. SteN builds on a database that stores the TIGR MtGI (release 8) TC composition and incorporates the Rstatistic of Stekel et al. (2000). Basically, this test statistic allows evaluation of gene expression on the basis of EST frequencies in different cDNA libraries. As a result, R-values are computed that can be used to rank differentially expressed genes proposed by in silico predictions, and in particular allows better separation of true- from false-positives (Stekel et al. 2000; Journet et al. 2002).

When applying the R-statistic (Stekel et al. 2000) to identify putative AM-specific genes of $M$. truncatula, we found that 669 TCs were exclusively composed of ESTs generated from the five comprehensive AM libraries listed in Table 1 or of two small collections of suppressivesubtractive hybridisation (SSH) ESTs from AM roots (Brechenmacher et al. 2004; Weidmann et al. 2004). It should be noted that the TC list contains some sequences that, in addition, rely on ESTs from curated clone collections, 

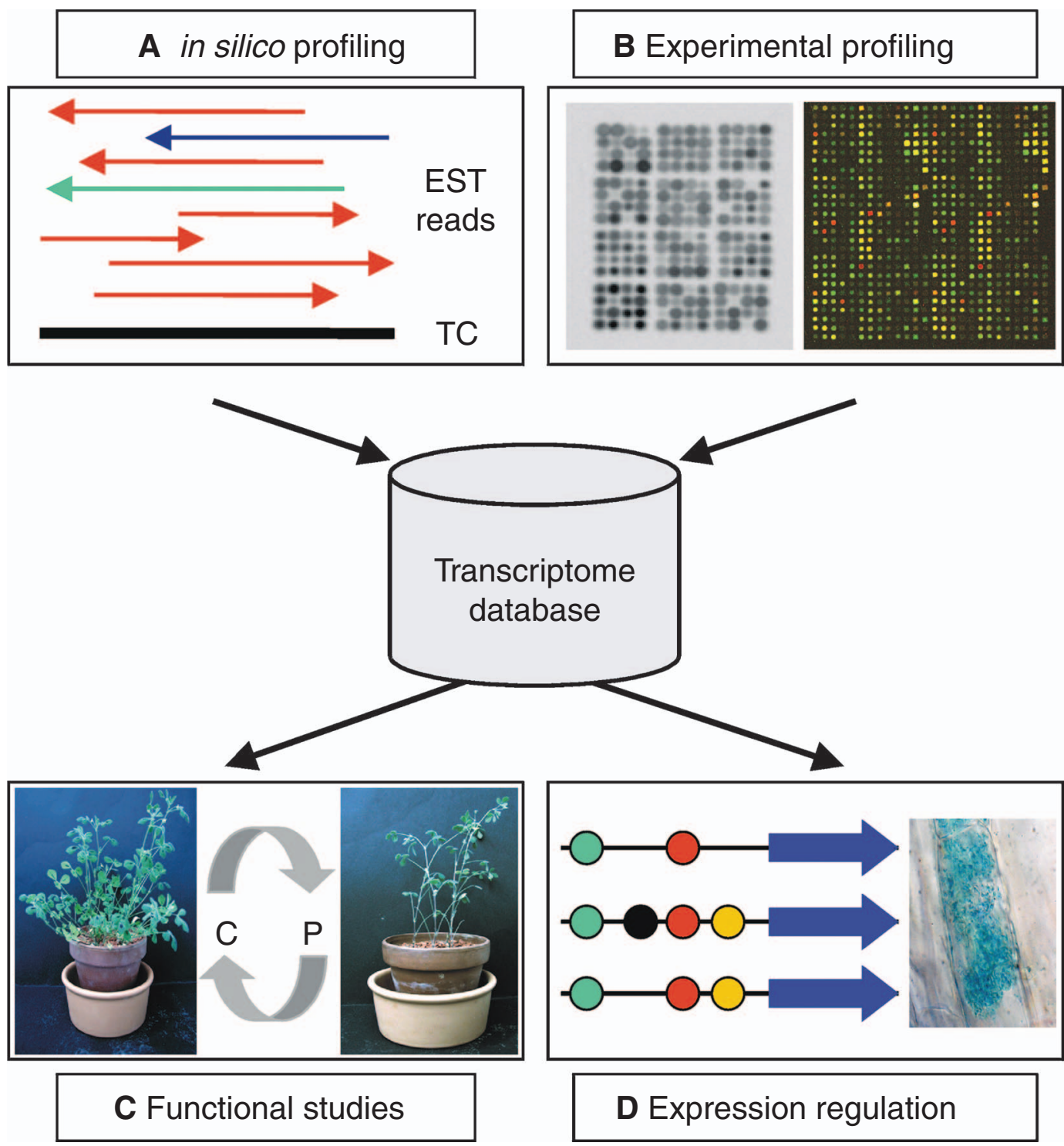

Fig. 1. Untargeted transcriptome profiling facilitates functional analyses of arbuscular mycorrhiza formation in Medicago truncatula. (A) An in silico expression profiling experiment, where the EST-composition of a particular $\mathrm{TC}$ is traced to derive information on the expression of the corresponding gene. In the example shown, red arrows denote ESTs from AM roots, whereas arrows with different colours represent ESTs from non-AM tissues. For the TC sequence assembled from these ESTs, an AM-induced expression can be predicted. $(B)$ Experimental expression profiling approaches based on macro- and microarray hybridisations. Together, in silico and experimental expression profiling strategies lead to the identification of genes differentially regulated during AM, and these data can be queried based on the use of appropriate transcriptome databases storing EST compositions as well as hybridisation data. Relying on the mining of transcriptome profiles from such databases, more targeted studies on the function $(C)$ and transcriptional regulation $(D)$ of AM-activated genes can be performed. Here, $(C)$ illustrates a phenotypic study that compares a wild type plant with a line mutated in an AM-relevant gene, with the underlying effect of the mutation on AM efficiency being symbolised by the exchange of phosphorus for carbon compounds. Finally, $(D)$ summarises approaches to study the expression regulation of genes activated in arbuscule-containing cells. Typically, these experiments rely on the expression analysis of reporter genes (symbolised by blue arrows) controlled by different promoter regions of genes expressed in arbuscules, as indicated by the reporter gene activity on the right. These regions can be compared to identify common motifs that mediate expression regulation. Motifs are symbolised by circles with different colours. In the example shown, the green and red motifs can be identified in all promoters tested and hence constitute putative binding sites for AM-specific transcriptional regulators. Abbreviations: $\mathrm{C}$, carbon compound; EST, expressed sequence tag; P, phosphorus; TC, tentative consensus sequence. 
such as the $6 \mathrm{k}$ unigene library, and the leguminosin library (http://www.tigr.org/tdb/tgi/). Since those ESTs also derive from AM libraries, this does not interfere with the prediction of an AM-specific expression. In addition, a few TCs contain expressed transcripts (ETs) e.g. deriving from targeted sequencing to characterise full-length cDNAs of AM-expressed genes.

In supplementary Table 1 (accessory publication, see website of Functional Plant Biology), all 669 TCs encoding putative AM-specific genes of M. truncatula are listed, together with their EST-composition and with R-values calculated according to Stekel et al. (2000). Looking at the distribution of EST-frequencies in the AM-specific TCs, it is evident that 128 TCs are composed of at least four ESTs (24 TCs with more than 10 ESTs), whereas the other TCs (541) are represented by, at most, three transcript sequences. The high proportion of TCs consisting of only a few ESTs is probably related to a dilution of AM structures in whole roots used for library construction and reflects the fact that most AM-activated genes are up-regulated only locally, e.g. in developing arbuscules.

To provide updated annotations for the predicted AMspecific genes, we used the 'Sequence Analysis and Management System' (SAMS) tool that is based on the GenDB software for automatic annotation of prokaryotic genomes (Meyer et al. 2003). In order to improve the automatic annotation of TCs, frameshift-corrected open reading frames were calculated from TIGR MtGI TC sequences using the frameD software (Schiex et al. 2003). Together with the TIGR MtGI 8 annotation, updated automatic annotations are included in supplementary Table 1.

When inspecting the EST contribution from the different AM cDNA libraries, 68 TCs were exclusively composed of MHAM or MHAM2 ESTs, whereas 86 TCs were composed of MtGIM and 14 TCs of MtAMP ESTs. A surprisingly high number of $343 \mathrm{TCs}$ were only built from ESTs of the MtBC library. This number can be explained by the fact that MtBC is the only library where $5^{\prime}$ and $3^{\prime}$ ESTs were generated, yielding 287 TCs exclusively composed of two MtBC ESTs. In most cases, those TCs are composed of ESTs defining the ends of only one cDNA. The existence of only 125 TCs where ESTs were obtained from at least two cDNA libraries most likely reflects differences in colonising fungi or in growth conditions of the AM roots used for library construction. Being confirmed by different experimental setups, these TCs are obviously prime candidates for AMinduced M. truncatula genes.

\section{Global approach III: suppressive subtractive hybridisations provide shortcuts to Medicago truncatula genes activated in arbuscular mycorrhiza}

Since random libraries contain a high proportion of strongly expressed genes and a limited proportion of genes expressed at a low level (Diatchenko et al. 1996), the analysis of SSH cDNA libraries can be expected to ease the identification of candidate genes with an AM-induced expression. One such library is MtGIM, generated from $M$. truncatula/G. intraradices AM roots (Table 1). During MtGIM construction, transcript sequences from uninfected roots, phosphate-supplemented roots, Sinorhizobium meliloti-infected roots and Aphanomyces euteiches-infected roots were subtracted to enrich for AMinduced genes. This strategy proved to be successful, given the comparably high proportion of 86 MtGIMspecific TCs generated from a moderate collection of 1686 ESTs (supplemental Table 1, Frenzel et al. 2005). In addition, the specific expression of most novel genes involvement in transport as well as signalling processes was verified by real-time RT-PCR, thus providing an independent confirmation of the in silico data (Frenzel et al. 2005).

The power of suppressive subtractive approaches to specify differentially expressed genes is also evident from two further SSH libraries covering early and late stages of the M. truncatula/G. mosseae interaction (Brechenmacher et al. 2004; Weidmann et al. 2004). In both cases, deep EST sequencing was not performed, but all cDNAs identified by reverse northerns or RT-PCR as mycorrhiza-induced were analysed in detail, revealing 29 M. truncatula genes activated during the appressorium stage and 12 genes induced during later stages of the symbiosis. Interestingly, 11 genes related to signalling, transcription and translation were not activated in a $M$. truncatula mutant where fungal infection of the root is impossible, although appressoria are formed. This indicated that these genes are related to AM establishment (Weidmann et al. 2004).

Owing to the fact that a high proportion of AMactivated genes was detected by $\mathrm{SSH}$, these approaches bridge untargeted EST sequencing and global transcriptome profiling. It must be stressed that, in particular, owing to the potential of identifying rare transcripts or genes expressed locally, SSH is usually not redundant but quite complementary to microarray-based transcriptome profiling.

\section{Global approach IV: array-based transcriptome profiling identifies Medicago truncatula genes activated in arbuscular mycorrhiza}

Three global transcriptome studies applying cDNA- and 70mer oligonucleotide-based macro- and microarrays (Fig. 1) have so far been reported in M. truncatula.

First, Liu et al. (2003) applied a macroarray based on 2268 unique cDNAs from the $M$. truncatula $/ G$. versiforme MHAM library mentioned above (Table 1) to identify genes up-regulated in response to Glomus versiforme at different stages of AM development. Based on hierarchical clustering, the authors identified two distinct temporal gene expression patterns in the course of the symbiotic interaction. Whereas the first group showed a peak in gene induction during 
early stages, including defence- and stress-response genes, genes from the second group displayed a constant increase in transcription that correlated with fungal colonisation. Since components of signal transduction pathways were transcriptionally induced in the latter group, novel AMrelated signalling pathways have been proposed. These signalling processes can be related to the maintenance and sustainability of fungal structures in root tissues and the specific activation of gene expression in arbuscule-containing cells.

Second, Manthey et al. (2004) performed a global transcriptome approach to identify genes activated in the $M$. truncatula $-G$. intraradices AM. This study relied on the Mt6kRIT ( $\underline{M}$. truncatula $\underline{6} \underline{\mathrm{k}} \underline{\text { Root Interaction }}$ Transcriptome) macro- and microarrays (Küster et al. 2004) that represent $\sim 6000$ EST clusters from an EST-sequencing project covering mycorrhization and nodulation ('MENS-Medicago EST Navigation System', http://medicago.toulouse.inra.fr/Mt/EST/; verified 16 June 2006; Journet et al. 2002). A major focus of this approach was to identify symbiotically induced genes upregulated both during mycorrhization and nodulation. Here, earlier targeted studies indicated that, in particular, genes expressed early during nodulation, e.g. the nodulin genes ENOD2, ENOD40, ENOD5, ENOD11, and ENOD12, are also transcriptionally activated during AM (van Rhijn et al. 1997; Albrecht et al. 1998; Chabaud et al. 2002; Journet et al. 2001). Based on Mt6kRIT array hybridisations, several hundred genes were detected as being up-regulated during different stages of nodule development (El Yahyaoui et al. 2004; Küster et al. 2004; Manthey et al. 2004), now allowing a more global comparison of the expression profiles during nodulation and mycorrhization. Although the development of the two endosymbioses shares common mechanisms such as the formation of intracellular infection structures, the intracellular colonisation of root tissues by symbiotic microorganisms, and the generation of symbiotic carbon sinks (Provorov et al. 2002; Genre et al. 2005), only a limited overlap of the genetic program activated during nodulation and mycorrhization was found, with 75 genes being co-induced in the two interactions (El Yahyaoui et al. 2004; Manthey et al. 2004). To a certain extent, this low overlap is due to a lack of cellular resolution and a dilution in particular of genes activated early during mycorrhization by non-mycorrhizal areas of the roots.

In a recent study, the more comprehensive Mt16kOLI1 70-mer oligonucleotide microarrays were applied to specify the overlapping genetic program activated by two commonly studied microsymbionts, Glomus mosseae and Glomus intraradices. In total, 201 plant genes were significantly co-induced at least 2-fold in either interaction (Hohnjec et al. 2005), using normalisation functions and statistical analysis pipelines implemented in EMMA, a database designed to store and evaluate expression profiles from spotted microarrays (Dondrup et al. 2003). A range of well known AM marker genes were found to be co-activated, thus validating the transcriptomics data. Among those were the phosphate transporter MtPt4 (Harrison et al. 2002), the germin-like protein MtGlp1 (Doll et al. 2003), the glutathione S-transferase MtGst1 (Wulf et al. 2003), the serine carboxypeptidase MtScp1 (Liu et al. 2003), the hexose transporter MtSt1 (Harrison 1996), the 1-deoxy-D-xylulose 5-phosphate synthase MtDXS2 (Walter et al. 2002), and a multifunctional aquaporin (Brechenmacher et al. 2004).

Apart from AM marker genes, more than 150 novel AM-induced genes were reported, among them genes specifying novel AM-related transporters, enzymes involved in secondary metabolism, and different proteases as well as protease inhibitors. With respect to signalling, several coinduced genes encoded putative components of signal transduction pathways as well as ten novel AM-induced transcriptional regulators (Hohnjec et al. 2005), including a Myb-like transcription factor initially reported by Liu et al. (2003). Several hundred genes were additionally up-regulated during the Glomus mosseae or the Glomus intraradices AM, adding to the global profiling data from Liu et al. (2003) as well as Manthey et al. (2004), and implying that the plant genetic program activated during AM to some extent depends on the microsymbiont or the batch of inoculum used.

Subsets of genes identified by the global transcriptome profiling studies were subjected to real-time RT-PCR for verification of their symbiosis-induced expression (Liu et al. 2003; Manthey et al. 2004; Hohnjec et al. 2005). These experiments allowed the conclusion that microarray-based expression data in general appear to be more reliable than in silico predictions (Manthey et al. 2004), an observation corroborating a theoretical consideration by Allison et al. (2006). Also, this conclusion resembles findings of Fedorova et al. (2002) and Tesfaye et al. (2006), who demonstrated that a TC has to be composed of a minimal number of ESTs to allow a robust expression prediction of the corresponding gene in root nodules.

Mt16kOLI1 oligonucleotide microarrays were designed on the basis of all TIGR MtGI release 5 TCs. Thus, expression data obtained with these arrays could be related to the in silico prediction of AM-induced genes from the TIGR MtGI. In supplemental Table 1, expression ratios of $M$. truncatula genes during the AM with $G$. mosseae and G. intraradices (Hohnjec et al. 2005) have been included. Since additional ESTs (including those from the MHAM2, the MtAMP and the MtGIM library; Table 1) were incorporated into the TIGR MtGI release 8, not all current TCs match oligonucleotide probes on Mt16kOLI1 microarrays. Nevertheless, for those TCs represented by many ESTs, there is a good overlap between in silico and experimental transcriptome profiles (supplemental Table 1). Not surprisingly, TCs represented by only a few ESTs were not reproducibly detected across the different biological replicates used for microarray hybridisation. In these cases, either the in silico profiles suffer from a lack of biological 
repetition or the microarray hybridisations fail to detect locally expressed genes that were detected by deep ESTsequencing.

\section{Cellular expression of Medicago truncatula genes in arbuscular mycorrhizal roots}

Adding to the identification of AM-induced genes by more targeted approaches (e.g. the proline-rich protein MtEnod11, Journet et al. 2001; the 1-deoxy-D-xylulose 5-phosphate synthase MtDXS2, Walter et al. 2002; the aquaporin Mtaqp1, Krajinski et al. 2000), untargeted in silico and experimental transcriptome profiling identified several hundred M. truncatula genes with a mycorrhiza-specific or a mycorrhiza-induced expression. While post-transcriptional mechanisms of expression regulation should not be neglected, this collection of genes forms a comprehensive basis for functional analyses of the encoded gene products.

Although a method allowing the rapid, synchronous root colonisation by AM fungi was reported by Rosewarne et al. (1997), it has not been widely applied in molecular AM research. Consequently, mycorrhizal roots containing different symbiotic structures were used for the transcriptomics experiments described above, and the expression profiles obtained cannot easily be connected to specific stages of the AM symbiosis. It is thus evident that global expression profiling approaches that rely on the analysis of pooled tissue samples suffer from a significant loss of biological information. Ultimately, the combination of high-throughput transcriptomics, e.g. by constructing cell-specific SSH cDNA libraries or by studying cell-specific gene expression via microarray hybridisations (Kehr 2003; Kerk et al. 2003), will be required.

Although so far, cellular high-throughput expression profiles are not available for the AM symbiosis, in situ localisation techniques have allowed specification of a cellular localisation of selected genes found to be transcriptionally activated during AM (Fig. 1; Table 2). These approaches relied on in situ transcript and protein localisations as well as on the expression of promoterreporter gene fusions in transgenic roots.

On the basis of EST analyses and macroarray hybridisations, Harrison etal. (2002) and Liu etal. (2003) studied the spatial expression pattern of three AM-induced genes by expressing reporter gene fusions in transgenic $M$. truncatula roots. Whereas the phosphate transporter MtPt4 and the endoglucanase MtCell were found to be expressed exclusively in arbuscule-containing cells, the serine carboxypeptidase MtScp1 was upregulated in discrete cell files of the roots, even if only some cells contained arbuscules. Based on these distinct expression patterns, Harrison (2005) proposed that gene expression in mycorrhizal roots is signalled both by cell-autonomous (expression in arbuscule-containing cells) and by non-cell-autonomous signals (expression in arbusculated cell files or additionally in cells surrounding arbuscules), a finding also supported by the promoter studies mentioned below.

A range of other AM marker genes of M. truncatula can be grouped into these two categories as well. Whereas arbusculespecific gene expression was reported for the MtGlp1 gene encoding a germin-like protein (Doll et al. 2003), the annexin gene MtAnn2 (Manthey et al. 2004), and the lectin genes MtLec5 and MtLec7 (Frenzel et al. 2005), expression in the arbuscule-containing as well as the surrounding root cells were reported for the glutathione-S-transferase gene MtGst1 (Wulf et al. 2003), the trypsin inhibitor gene MtTil (Grunwald et al. 2004), the $\beta$-tubulin gene MtTubb1 (Manthey et al. 2004), the truncated hemoglobin gene MtTrHb2 (Vieweg et al. 2005), and the MtBcp1 gene specifying a blue-copper-binding protein (bcp) (Hohnjec et al. 2005). Whereas MtTrHb2, MtTubb1 and MtAnn2 were also activated during nodulation, the other genes appear to be specifically up-regulated during mycorrhization.

The first AM-activated gene with relevance to the physiology of arbuscule-containing cells were two plasma membrane $\mathrm{H}^{+}$-ATPases found to be expressed in arbusculecontaining cells of tobacco roots and the corresponding protein and enzyme activities were localised to the periarbuscular membrane (Gianinazzi-Pearson et al. 2000). In M. truncatula, the $\mathrm{H}^{+}$-ATPase MtHa1 protein has recently been localised to the periarbuscular membrane by proteomics approaches (Valot et al. 2006). In addition to being expressed in AM roots (Krajinski et al. 2002) and similar to other AM-induced genes, MtHal was also found to be induced during nodulation, illustrating the common requirement for an acidification of the perisymbiotic space in either root endosymbiosis (Manthey et al. 2004), probably to support energy-dependent transport processes.

A particularly interesting arbuscule-specific gene is MtBcp1. This gene is part of a family of tandemly arranged genes, all of them specifically and strongly induced in AM (Wulf et al. 2003; Frenzel et al. 2005; Hohnjec et al. 2005). MtBcp1 encodes a bcp with a predicted glycosylphosphatidylinositol (GPI) anchor (Valot et al. 2006). Bcp proteins usually contain a single copper atom and are implicated in electron transfer reactions, such as the chloroplastic plastocyanins that exchange electrons with cytochromes (Hohnjec et al. 2005). Together with the plasma membrane ATPase MtHa1 (Krajinski et al. 2002), MtBcp1 was recently localised in the periarbuscular membrane, probably being inserted via its GPI-anchor (Valot et al. 2006).

Whereas the biological function of some AM-induced genes is obvious, e.g. the modification of cytoskeletal structure for MtTubb1, the acidification of the periarbuscular space for MtHal and phosphate transfer to the plant for MtPT4, the function of MtBcp1 remains elusive. This also holds true for other arbuscule-specific or arbusculeinduced genes that were connected to detoxification processes (MtGst1) and the suppression of plant defence (MtTi1, MtTrHb2), or that were related to 


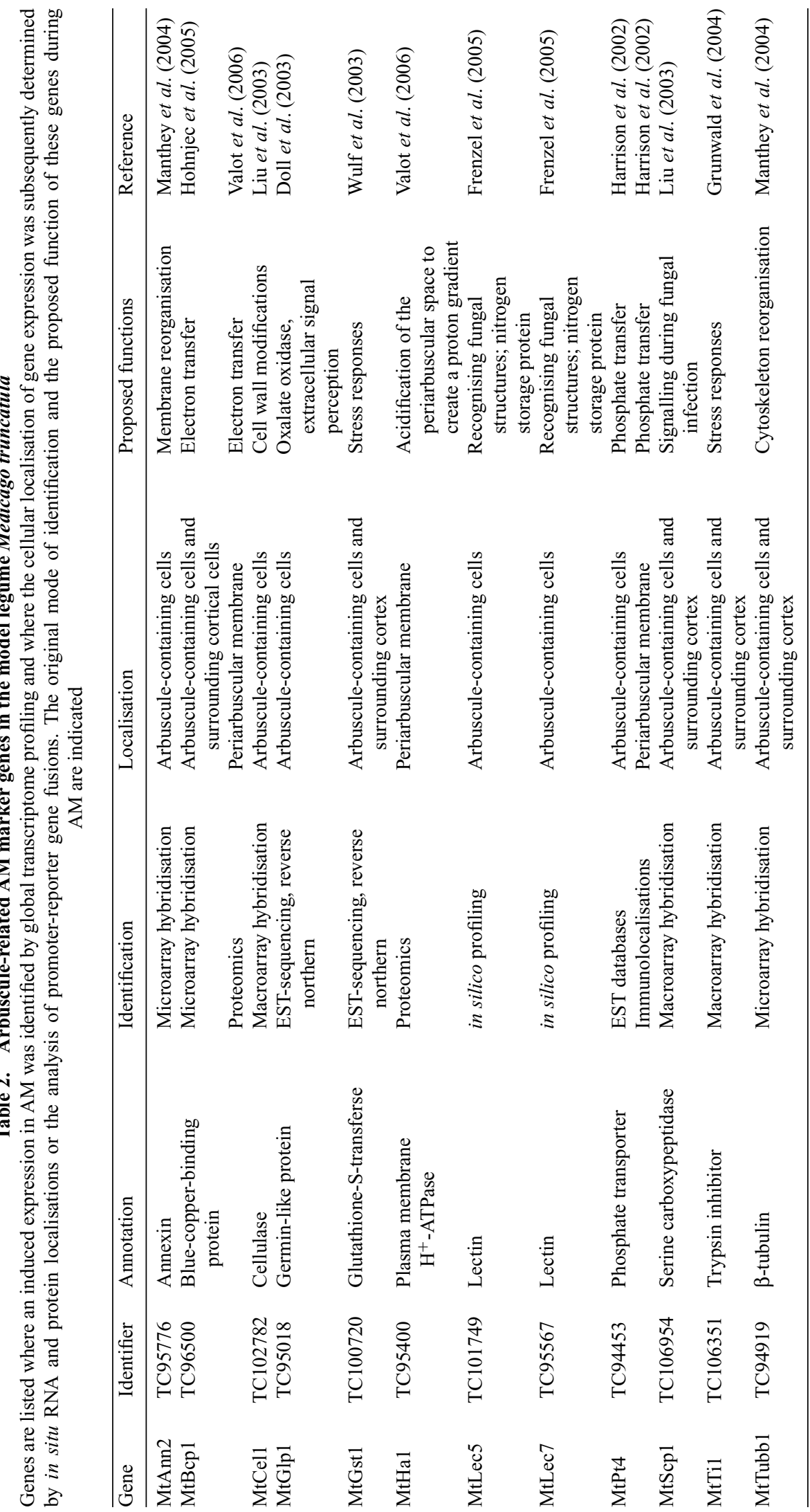


signalling (MtGlp1, MtLec5 and MtLec6). Detailed reverse genetics studies using mutants or RNAi approaches (Tadege et al. 2005; Isayenkov et al. 2005; Ivashuta et al. 2005) will be required to establish biological functions for these genes during AM (Fig. 1). It should be kept in mind that several AM-induced genes belong to large gene families, a finding e.g. reported by Salzer et al. (2000) for eight M. truncatula chitinase genes that were differentially expressed not only in $\mathrm{AM}$, but also during other symbiotic and pathogenic plant-microbe interactions. Studying gene families opens the challenging opportunity to identify more fine-tuned functional properties of those members specifically activated during AM.

\section{Towards a molecular basis of gene expression regulation in arbuscular mycorrhiza}

So far, hundreds of AM-induced M. truncatula genes have been identified by in silico and experimental expression profiling experiments, and the full-size promoters of several genes have been tested for gene expression in AM (see Table 2). Although these studies led to a collection of $M$. truncatula promoters that are exclusively or predominantly expressed in arbuscule-containing cells of mycorrhizal roots (e.g. Journet et al. 2001; Harrison et al. 2002; Krajinski et al. 2002; Wulf et al. 2003; Grunwald et al. 2004; Manthey et al. 2004; Vieweg et al. 2004; Frenzel et al. 2005; Hohnjec et al. 2005), little is known about the promoter elements that mediate gene expression in arbusculecontaining cells.

In the promoter of the MtPt4 gene encoding the AMspecific phosphate transporter of M. truncatula, Harrison et al. (2002) identified a sequence sharing some similarity with a mycorrhiza- and resistance-related element (MRR1) reported for the promoter of the AM-specific phosphate transporter StPT3 from potato (Rausch et al. 2001), but this element was not reported to be present or functional in other genes activated in arbuscule-containing cells.

Recently, Boisson-Dernier et al. (2005) presented a detailed loss-of-function study of the MtEnod11 promoter. The MtEnod11 gene encoding a proline-rich protein is particularly interesting, since it is activated by Nod-factors, $S$. meliloti infection, diffusible factors from AM fungi and during AM formation (Journet et al. 2001; Kosuta et al. 2003). The loss-of-function study specified the -257 promoter region as sufficient to drive gene expression in AM roots. In this region, an AT-rich regulatory sequence known from other early nodulin gene promoters was identified. Interestingly, site-directed mutagenesis of this element led to a significant reduction of gene expression both during $S$. meliloti infection and in AM. Since the -257 promoter region is apparently not sufficient for Nod-factorinduced gene expression, it appears that different modules of the promoter are responsible for different symbiotic gene activations (Boisson-Dernier et al. 2005).
A similar observation was made for the promoter of the Vicia faba leghemoglobin gene VfLb29. This gene was initially identified by reverse northern hybridisations (Frühling et al. 1997) and was recently found to be exclusively expressed in the infected cells of root nodules and in the arbuscule-containing cells of arbuscular mycorrhizal roots of different legume and non-legume plants (Vieweg et al. 2004). A loss-of-function approach led to the identification of an 85-bp region (position -410 to -326 relative to the start codon) that is required for expression in arbuscule-containing cells, although being dispensable for gene activation in nodules. To investigate an autonomous function of the 85-bp region in arbuscule-containing cells, gain-of-function approaches were performed with chimeric promoter constructs. Since a trans-activation by the 85-bp region was not achieved, it appears that the activation of the VfLb29 promoter in arbuscule-containing cells is governed by a complex system requiring at least two regulatory modules (Fig. 1; Fehlberg et al. 2005). Thus, although detailed promoter studies in AM roots are obviously far from comprehensive, it emerges that the situation is more complex than in the root nodule symbiosis where organspecific-elements (OSEs) were reported to be sufficient to direct gene expression to the infected cells of root nodules (Stougaard et al. 1987).

Clearly, the detailed molecular analysis of more AMspecific promoters will be required to specify core elements responsible for gene activation in arbuscule-containing cells. The global transcriptome profiling experiments presented above delivered a collection of AM-induced genes that, together with upcoming information on promoters from the M. truncatula genome sequence, can be the basis for more genome-wide analyses of promoter motifs regulating gene expression during AM.

\section{Conclusions}

The application of untargeted transcriptome profiling has provided novel insights into the molecular basis of AM development, but the lack of cellular resolution in these high-throughput expression approaches makes it difficult to determine the symbiotic stage or the cell types where AMactivated genes are important. A major future challenge will thus be to develop and apply single-cell profiling techniques to specify the transcriptome of characteristic symbiotic cells, e.g. epidermal cells in contact with appressoria, cells surrounding the infecting hyphae, and cells harbouring arbuscules of different developmental stages. The second challenge will be to overcome the lack of knowledge on transcriptional regulators controlling the formation and sustainability of the AM symbiosis. The identification of such regulators will be facilitated by the development of real-time RT-PCR platforms targeted at the robust detection of transcription factor gene expression (Czechowski et al. 2004). Finally, it should be kept in mind that an understanding 
of the 'system' AM will only be possible by analysing the transcriptional reprogramming in the two genomes that mastermind the development of AM roots. The ongoing genome project in the model AM fungus $G$. intraradices is a first step towards this direction and the future availability of whole-genome microarrays covering the genomes of the macro- as well as the microsymbiont can be expected to jumpstart another era in AM research.

\section{Acknowledgments}

This work was supported by the Deutsche Forschungsgemeinschaft SPP 1084 'Mykorrhiza' as well as by the European Union projects MEDICAGO (QLGCT2000-00676) and GRAIN LEGUMES (FOOD-CT-2004506223). HK, MD and NH acknowledge financial support by the International Graduate School in Bioinformatics and Genome Research. The work of AG and TB was funded by the Bundesministerium für Bildung und Forschung (BMBF 0313105).

\section{References}

Alba R, Zhangjun F, Payton P, Liu Y, Moore SL, et al. (2004) ESTs, cDNA microarrays, and gene expression profiling: tools for dissecting plant physiology and development. The Plant Journal 39, 697-714. doi:10.1111/j.1365-313X.2004.02178.x

Albrecht C, Geurts R, Lapeyrie F, Bisseling T (1998) Endomycorrhizae and rhizobial Nod factors both require SYM8 to induce the expression of the early nodulin genes PsENOD5 and PsENOD12A. The Plant Journal 15, 605-614. doi: 10.1046/j.1365313x.1998.00228.x

Allison DB, Cui X, Page GP, Sabripour M (2006) Microarray data analysis: from disarray to consolidation and consensus. Nature Reviews. Genetics 7, 55-65. doi: 10.1038/nrg 1749

Bago B, Pfeffer PE, Shachar-Hill Y (2000) Carbon metabolism and transport in arbuscular mycorrhizas. Plant Physiology 124, 949-958. doi: 10.1104/pp.124.3.949

Barker DG, Bianchi S, Blondon F, Dattée Y, Duc G, et al. (1990) Medicago truncatula, a model plant for studying the molecular genetics of the Rhizobium-legume symbiosis. Plant Molecular Biology Reporter 8, 40-49.

Boisson-Dernier A, Andriankaja A, Chabaud M, Niebel A, Journet E-P, Barker DG, de Carvalho-Niebel F (2005) MtEnod11 gene activation during rhizobial infection and mycorrhizal arbuscule development requires a common AT-rich-containing regulatory sequence. Molecular Plant-Microbe Interactions 18, 1269-1276.

Bonfante P, Perotto S (1995) Strategies of arbuscular mycorrhizal fungi when infecting host plants. New Phytologist 130, 3-21. doi: $10.1111 / \mathrm{j} .1469-8137.1995 . t b 01810 . x$

Brechenmacher L, Weidmann S, van Tuinen D, Chatagnier O, Gianinazzi S, Franken P, Gianinazzi-Pearson V (2004) Expression profiling of up-regulated plant and fungal genes in early and late stages of Medicago truncatula-Glomus mosseae interactions. Mycorrhiza 14, 253-262. doi: 10.1007/s00572-003-0263-4

Brewin NJ (1991) Development of the legume root nodule. Annual Review of Cell Biology 7, 191-226. doi: 10.1146/break annurev.cb.07.110191.001203

Chabaud M, Venard C, Defaux-Petras A, Bécard G, Barker DG (2002) Targeted inoculation of Medicago truncatula in vitro root cultures reveals MtENOD11 expression during early stages of infection by arbuscular mycorrhizal fungi. New Phytologist 156, 265-273. doi: 10.1046/j.1469-8137.2002.00508.x
Colebatch G, Kloska S, Trevaskis B, Freund S, Altmann T, Udvardi MK (2002) Novel aspects of symbiotic nitrogen fixation uncovered by transcript profiling with cDNA arrays. Molecular Plant-Microbe Interactions 15, 411-420.

Colebatch G, Desbrosses G, Ott T, Krusell L, Montanari O, Kloska S, Kopka J, Udvardi MK (2004) Global changes in transcription orchestrate metabolic differentiation during symbiotic nitrogen fixation in Lotus japonicus. The Plant Journal 39, 487-512. doi: 10.1111/j.1365-313X.2004.02150.x

Cullimore J, Dénarié J (2003) How legumes select their sweet talking symbionts. Science 302, 575-578. doi: 10.1126/science.1091269

Czechowski T, Bari RP, Stitt M, Scheible WR, Udvardi MK (2004) Real-time RT-PCR profiling of over 1400 Arabidopsis transcription factors: unprecedented sensitivity reveals novel root- and shootspecific genes. The Plant Journal 38, 366-379. doi: 10.1111/j.1365313X.2004.02051.x

Diatchenko L, Lau YF, Campbell AP, Chenchik A, Moqadam F, et al. (1996) Suppression subtractive hybridization: a method for generating differentially regulated or tissue-specific cDNA probes and libraries. Proceedings of the National Academy of Sciences USA 93, 6025-6030. doi: 10.1073/pnas.93.12.6025

Doll J, Hause B, Demchenko K, Pawlowski K, Krajinski F (2003) A member of the germin-like protein family is a highly conserved mycorrhiza-specific induced gene. Plant \& Cell Physiology 44, 1208-1214. doi: 10.1093/pcp/pcg153

Dondrup M, Goesmann A, Bartels D, Kalinowski J, Krause L, Linke B, Rupp O, Szyrba A, Pühler A, Meyer F (2003) EMMA: a platform for consistent storage and efficient analysis of microarray data. Journal of Biotechnology 106, 135-146. doi: 10.1016/j.jbiotec.2003.08.010

El Yahyaoui F, Küster H, Ben Amor B, Hohnjec N, Pühler A, et al. (2004) Expression profiling in Medicago truncatula identifies more than 750 genes differentially expressed during nodulation, including many potential regulators of the symbiotic program. Plant Physiology 136, 3159-3176. doi: 10.1104/pp.104.043612

Fedorova M, van de Mortel J, Matsumoto PA, Cho J, Town CD, VandenBosch KA, Gantt JS, Vance CP (2002) Genomewide identification of nodule-specific transcripts in the model legume Medicago truncatula. Plant Physiology 130, 519-537. doi: 10.1104/pp.006833

Fehlberg V, Vieweg MF, Dohmann EMN, Hohnjec N, Pühler A, Perlick AM, Küster H (2005) The promoter of the leghaemoglobin gene VfLb29: functional analysis and identification of modules necessary for its activation in the infected cells of root nodules and in the arbuscule-containing cells of mycorrhizal roots. Journal of Experimental Botany 56, 799-806. doi: 10.1093/jxb/eri074

Ferrol N, Pozo MJ, Antelo M, Azcon-Aguilar C (2002) Arbuscular mycorrhizal symbiosis regulates plasma membrane $\mathrm{H}^{+}$-ATPase gene expression in tomato plants. Journal of Experimental Botany 53, 1683-1687. doi: 10.1093/jxb/erf014

Franken P, Requena N (2001) Analysis of gene expression in arbuscular mycorrhiza: new approaches and challenges. New Phytologist 150, 431-439.

Frenzel A, Manthey K, Perlick AM, Meyer F, Pühler A, Krajinski F, Küster H (2005) Combined transcriptome profiling reveals a novel family of arbuscular mycorrhizal-specific Medicago truncatula lectin genes. Molecular Plant-Microbe Interactions 18, 771-782.

Frühling M, Roussel H, Gianinazzi-Pearson V, Pühler A, Perlick AM (1997) The Vicia faba leghemoglobin gene VfLb29 is induced in root nodules and in roots colonized by the arbuscular mycorrhizal fungus Glomus fasciculatum. Molecular Plant-Microbe Interactions 10, 124-131.

Genre A, Chabaud M, Timmers T, Bonfante P, Barker DG (2005) Arbuscular mycorrhizal fungi elicit a novel intracellular apparatus in Medicago truncatula root epidermal cells before infection. The Plant Cell 17, 3489-3499. doi: 10.1105/tpc.105.035410 
Geurts R, Fedorova E, Bisseling T (2005) Nod factor signaling genes and their function in the early stages of Rhizobium infection. Current Opinion in Plant Biology 8, 346-352. doi: 10.1016/j.pbi.2005.05.013

Gianinazzi-Pearson V (1996) Plant cell responses to arbuscular mycorrhizal fungi: getting to the roots of the symbiosis. The Plant Cell 8, 1871-1883. doi: 10.1105/tpc.8.10.1871

Gianinazzi-Pearson V, Dénarié J (1997) Red carpet genetic programmes for root endosymbioses. Trends in Plant Science 2, 371-372. doi: 10.1016/S1360-1385(97)87120-8

Gianinazzi-Pearson V, Brechenmacher L (2004) Functional genomics of arbuscular mycorrhiza: decoding the symbiotic cell programme. Canadian Journal of Botany 82, 1228-1234. doi: 10.1139/ b04-096

Gianinazzi-Pearson V, Arnould C, Oufattole M, Arango M, Gianinazzi S (2000) Differential activation of $\mathrm{H}^{+}$-ATPase genes by an arbuscular mycorrhizal fungus in root cells of transgenic tobacco. Planta 211, 609-613. doi: 10.1007/s004250000323

Graham JH, Miller M (2005) Mycorrhizas: gene to function. Plant and Soil 274, 79-100. doi: 10.1007/s11104-004-1419-5

Grunwald U, Nyamsuren O, Tamasloukht M, Lapopin L, Becker A, Mann P, Gianinazzi-Pearson V, Krajinski F, Franken P (2004) Identification of mycorrhiza-regulated genes with arbuscule development-related expression profile. Plant Molecular Biology 55, 553-566. doi: 10.1007/s11103-004-1303-y

Handberg K, Stougaard J (1992) Lotus japonicus, an autogamous, diploid legume species for classical and molecular genetics. The Plant Journal 2, 487-496. doi: 10.1111/j.1365-313X. 1992.00487.x

Harrison MJ (1996) A sugar transporter from Medicago truncatula: altered expression pattern in roots during vesicular-arbuscular (VA) mycorrhizal associations. The Plant Journal 9, 491-503. doi: 10.1046/j.1365-313X.1996.09040491.x

Harrison MJ (1997) The arbuscular mycorrhizal symbiosis: an underground association. Trends in Plant Science 2, 54-60. doi: 10.1016/S1360-1385(97)82563-0

Harrison MJ (1999) Molecular and cellular aspects of the arbuscular mycorrhizal symbiosis. Annual Review of Plant Physiology and Plant Molecular Biology 50, 361-389. doi: 10.1146/annurev.arplant.50.1.361

Harrison MJ (2005) Signaling in the arbuscular mycorrhizal symbiosis. Annual Review of Microbiology 59, 19-42. doi: 10.1146/annurev.micro.58.030603.123749

Harrison MJ, Dewbre GR, Liu J (2002) A phosphate transporter from Medicago truncatula involved in the acquisition of phosphate released by arbuscular mycorrhizal fungi. The Plant Cell 14, 2413-2429. doi: $10.1105 /$ tpc.004861

Hijri M, Sanders IR (2004) The arbuscular mycorrhizal fungus Glomus intraradices is haploid and has a small genome size in the lower limit of eukaryotes. Fungal Genetics and Biology 41, 253-261. doi: 10.1016/j.fgb.2003.10.011

Hohnjec N, Vieweg MF, Pühler A, Becker A, Küster H (2005) Overlaps in the transcriptional profiles of Medicago truncatula roots inoculated with two different Glomus fungi provide insights into the genetic program activated during arbuscular mycorrhiza. Plant Physiology 137, 1283-1301. doi: 10.1104/ pp.104.056572

Hraber PT, Weller JW (2001) On the species of origin: diagnosing the source of symbiotic transcripts. Genome Biology 2, research 0037.1-0037.14. doi: 10.1186/gb-2001-2-9-research0037

Isayenkov S, Mrosk C, Stenzel I, Strack D, Hause B (2005) Suppression of allene oxide cyclase in hairy roots of $M$. truncatula reduces jasmonate levels and the degree of mycorrhization with Glomus intraradices. Plant Physiology 139, 1401-1410. doi: $10.1104 /$ pp.105.069054
Ivashuta S, Liu J, Liu J, Lohar DP, Haridas S, Bucciarelli B, VandenBosch KA, Vance CP, Harrison MJ, Gantt JS (2005) RNA interference identifies a calcium-dependent protein kinase involved in Medicago truncatula root development. The Plant Cell 17, 2911-2921. doi: 10.1105/tpc.105.035394

Journet EP, El-Gachtouli N, Vernoud V, de Billy F, Pichon M, Dedieu A, Arnould C, Morandi D, Barker DG, Gianinazzi-Pearson V (2001) Medicago truncatula ENOD11: a novel RPRP-encoding early nodulin gene expressed during mycorrhization in arbusculecontaining cells. Molecular Plant-Microbe Interactions 14, 737-748.

Journet EP, van Tuinen D, Gouzy J, Crespeau H, Carreau V, et al. (2002) Exploring root symbiotic programs in the model legume Medicago truncatula using EST analysis. Nucleic Acids Research 30, 5579-5592. doi: 10.1093/nar/gkf685

Kehr J (2003) Single cell technology. Current Opinion in Plant Biology 6, 617-621. doi: 10.1016/j.pbi.2003.09.002

Kerk NM, Ceserani T, Tausta SL, Sussex IM, Nelson TM (2003) Laser capture microdissection of cells from plant tissues. Plant Physiology 132, 27-35. doi: 10.1104/pp.102.018127

Kistner C, Parniske M (2002) Evolution of signal transduction intracellular symbiosis. Trends in Plant Science 7, 511-518. doi: 10.1016/S1360-1385(02)02356-7

Kistner C, Winzer T, Pitzschke A, Mulder L, Sato S, et al. (2005) Seven Lotus japonicus genes required for transcriptional reprogramming of the root during fungal and bacterial symbiosis. The Plant Cell 17, 2217-2229. doi: $10.1105 /$ tpc. 105.032714

Kosuta S, Chabaud M, Lougnon G, Gough C, Dénarié J, Barker DG, Bécard G (2003) A diffusible factor from arbuscular mycorrhizal fungi induces symbiosis-specific MtENOD11 expression in roots of Medicago truncatula. Plant Physiology 131, 952-962. doi: 10.1104/pp.011882

Kouchi H, Shimomura K, Hata S, Hirota A, Wu G-J, et al. (2004) Large-scale analysis of gene expression profiles during early stages of root nodule formation in a model legume, Lotus japonicus. DNA Research 11, 263-274. doi: 10.1093/dnares/11.4.263

Krajinski F, Biela A, Schubert D, Gianinazzi-Pearson V, Kaldenhoff R, Franken P (2000) Arbuscular mycorrhiza development regulates the mRNA abundance of Mtaqp1 encoding a mercury-insensitive aquaporin of Medicago truncatula. Planta 211, 85-90. doi: $10.1007 / \mathrm{s} 004250000263$

Krajinski F, Hause B, Gianinazzi-Pearson V, Franken P (2002) Mtha1, a plasma membrane $\mathrm{H}^{+}$-ATPase gene from Medicago truncatula, shows arbuscule-induced expression. Plant Biology 4, 754-761. doi: $10.1055 / \mathrm{s}-2002-37407$

Küster H, Hohnjec N, Krajinski F, El Yahyaoui F, Manthey K, et al. (2004) Construction and validation of cDNA-based Mt6k-RIT macro- and microarrays to explore root endosymbioses in the model legume Medicago truncatula. Journal of Biotechnology $\mathbf{1 0 8}$, 95-113. doi: 10.1016/j.jbiotec.2003.11.011

Lammers P, Tuskan GA, DiFazio SP, Podila GK, Martin F (2004) Mycorrhizal symbionts of Populus to be sequenced by the United States Department of Energy's Joint Genome Institute. Mycorrhiza 14, 63-64. doi: 10.1007/s00572-003-0288-8

Limpens E, Bisseling T (2003) Signaling in symbiosis. Current Opinion in Plant Biology 6, 343-350. doi: 10.1016/S1369-5266(03)00068-2

Liu J, Blaylock LA, Endre G, Cho J, Town CD, VandenBosch KA, Harrison MJ (2003) Transcript profiling coupled with spatial expression analyses reveals genes involved in distinct developmental stages of an arbuscular mycorrhizal symbiosis. The Plant Cell 15, 2106-2123. doi: 10.1105/tpc.014183

Lohar DP, Sharopova N, Endre S, Peñuela S, Samac D, Town C, Silverstein KAT, VandenBosch KA (2006) Transcript analysis of early nodulation events in Medicago truncatula. Plant Physiology 140, 221-234. doi: 10.1104/pp.105.070326 
Manthey K, Krajinski F, Hohnjec N, Firnhaber C, Pühler A, Perlick AM, Küster H (2004) Transcriptome profiling in root nodules and arbuscular mycorrhiza identifies a collection of novel genes induced during Medicago truncatula root endosymbioses. Molecular Plant-Microbe Interactions 17, 1063-1077.

Martin F, Tuskan GA, DiFazio SP, Lammers P, Newcombe G, Podila GK (2004) Symbiotic sequencing of the Populus mesocosm. New Phytologist 161, 330-335. doi: 10.1111/j.1469-8137. 2004.00982.x

Meyer F, Goesmann A, McHardy AC, Bartels D, Bekel T, et al. (2003) GenDB: an open source genome annotation system for prokaryote genomes. Nucleic Acids Research 31, 2187-2195. doi: $10.1093 / \mathrm{nar} / \mathrm{gkg} 312$

Parniske M (2000) Intracellular accommodation of microbes by plants: a common developmental program for symbiosis and disease? Current Opinion in Plant Biology 3, 320-328. doi: 10.1016/S1369-5266(00)00088-1

Provorov NA, Borisov AY, Tikhonovich IA (2002) Developmental genetics and evolution of symbiotic structures in nitrogen-fixing nodules and arbuscular mycorrhiza. Journal of Theoretical Biology 214, 215-232. doi: 10.1006/jtbi.2001.2453

Quackenbush J, Cho J, Lee D, Liang F, Holt I, Karamycheva S, Parvici B, Pertea G, Sultana R, White J (2001) The TIGR Gene Indices: analysis of gene transcript sequences in highly sampled eukaryotic species. Nucleic Acids Research 29, 159-164. doi: 10.1093/nar/29.1.159

Rausch C, Daram P, Brunner S, Jansa J, Laloi M, Leggewie G, Amrhein N, Bucher M (2001) A phosphate transporter expressed in arbuscule-containing cells of potato. Nature 414, 462-466. doi: $10.1038 / 35106601$

Requena N, Breuninger M, Franken P, Ocon A (2003) Symbiotic status, phosphate, and sucrose regulate the expression of two plasma membrane $\mathrm{H}^{+}$-ATPase genes from the mycorrhizal fungus Glomus mosseae. Plant Physiology 132, 1540-1549. doi: 10.1104/pp.102.019042

Rosewarne GM, Barker SJ, Smith SE (1997) Production of nearsynchronous fungal colonization in tomato for developmental and molecular analyses of mycorrhiza. Mycological Research 101, 966-970. doi: 10.1017/S0953756297003626

Salzer P, Bonanomi A, Beyer K, Vogeli-Lange R, Aeschbacher RA, Lange J, Wiemken A, Kim D, Cook DR, Boller T (2000) Differential expression of eight chitinase genes in Medicago truncatula roots during mycorrhiza formation, nodulation, and pathogen infection. Molecular Plant-Microbe Interactions 13, 763-777.

Sato S, Tabata S (2006) Lotus japonicus as a platform for legume research. Current Opinion in Plant Biology 9, 128-132. doi: 10.1016/j.pbi.2006.01.008

Schiex T, Gouzy J, Moisan A, de Oliveira Y (2003) FrameD: a flexible program for quality check and gene prediction in prokaryotic genomes and noisy matured eukaryotic sequences. Nucleic Acids Research 31, 3738-3741. doi: 10.1093/nar/gkg610

Schüssler A, Schwarzott D, Walker C (2001) A new fungal phylum, the Glomeromycota: phylogeny and evolution. Mycological Research 105, 1413-1421.

Shachar-Hill Y, Pfeffer PE, Douds D, Osman SF, Doner LW, Ratcliffe RG (1995) Partitioning of intermediate carbon metabolism in VAM colonized leek. Plant Physiology 108, 7-15.

Smith SE, Dickson S, Smith FA (2001) Nutrient transfer in arbuscular mycorrhizas: how are fungal and plant processes integrated? Australian Journal of Plant Physiology 28, 683-694.

Smith SE, Read DJ (1997) 'Mycorrhizal symbiosis.' (Academic Press: London)

Stacey G, Libault M, Brechenmacher L, Wan J, May GD (2006) Genetics and functional genomics of legume nodulation. Current Opinion in Plant Biology 9, 110-121. doi: 10.1016/j.pbi.2006.01.005
Stekel DJ, Git Y, Falciani F (2000) The comparison of gene expression from multiple cDNA libraries. Genome Research 10, 2055-2061. doi: 10.1101/gr.GR-1325RR

Stougaard J, Sandal N, Gron A, Kuhle A, Marcker K (1987) 5' analysis of the soybean leghaemoglobin lbc3 gene: regulatory elements required for promoter activity and organ specificity. EMBO Journal 6, 3565-3569.

Tadege M, Ratet P, Mysore KS (2005) Insertional mutagenesis: a Swiss Army knife for functional genomics of Medicago truncatula. Trends in Plant Science 10, 229-235. doi: 10.1016/j.tplants.2005.03.009

Tesfaye M, Samac DA, Vance CP (2006) Insights into symbiotic nitrogen fixation in Medicago truncatula. Molecular PlantMicrobe Interactions 19, 330-341.

Town CD (2006) Annotating the genome of Medicago truncatula. Current Opinion in Plant Biology 9, 122-127. doi: 10.1016/j.pbi.2006.01.004

Udvardi MK, Tabata S, Parniske M, Stougaard J (2005) Lotus japonicus: legume research in the fast lane. Trends in Plant Science 10, 222-228. doi: 10.1016/j.tplants.2005.03.008

Valot B, Negroni L, Zivy M, Gianinazzi S, Dumas-Gaudot E (2006) A mass spectrometric approach to identify arbuscular mycorrhizarelated proteins in root plasma membrane fractions. Proteomics 6 , S145-S155 doi: 10.1002/pmic.200500403

van Rhijn P, Fang Y, Galili S, Shaul O, Atzmon N, et al. (1997) Expression of early nodulin genes in alfalfa mycorrhizae indicates that signal transduction pathways used in forming arbuscular mycorrhizae and Rhizobium-induced nodules may be conserved. Proceedings of the National Academy of Sciences USA 94, 5467-5472. doi: 10.1073/pnas.94.10.5467

Vessey KJ, Pawlowski K, Bergman B (2005) Root-based $\mathrm{N}_{2}$-fixing symbioses: legumes, actinorhizal plants, Parasponia sp. and cycads. Plant and Soil 274, 51-78. doi: 10.1007/s11104-005-5881-5

Vieweg MF, Frühling M, Quandt H-J, Heim U, Bäumlein H, Pühler A, Küster H, Perlick AM (2004) The promoter of the Vicia faba L. leghemoglobin gene VfLb29 is specifically activated in the infected cells of root nodules and in the arbuscule-containing cells of mycorrhizal roots from different legume and nonlegume plants. Molecular Plant-Microbe Interactions 17, 62-69.

Vieweg MF, Hohnjec N, Küster H (2005) Two genes encoding different truncated hemoglobins are regulated during root nodule and arbuscular mycorrhiza symbioses of Medicago truncatula. Planta 220, 757-766. doi: 10.1007/s00425-004-1397-0

Walter MH, Hans J, Strack D (2002) Two distantly related genes encoding 1-deoxy-D-xylulose 5-phosphate synthases: differential regulation in shoots and apocarotenoid-accumulating mycorrhizal roots. The Plant Journal 31, 243-254. doi: 10.1046/j.1365313X.2002.01352.x

Weidmann S, Sanchez L, Descombin J, Chatagnier O, Gianinazzi S, Gianinazzi-Pearson V (2004) Fungal elicitation of signal transduction-related plant genes precedes mycorrhiza establishment and requires the dmi3 gene in Medicago truncatula. Molecular Plant-Microbe Interactions 17, 1385-1393.

Wulf A, Manthey K, Doll J, Perlick AM, Linke B, Bekel T, Meyer F, Franken P, Küster H, Krajinski F (2003) Transcriptional changes in response to arbuscular mycorrhiza development in the model plant Medicago truncatula. Molecular Plant-Microbe Interactions 16, 306-314.

Young ND, Cannon SB, Sato S, Kim D, Cook DR, Town CD, Roe BA, Tabata S (2005) Sequencing the genespaces of Medicago truncatula and Lotus japonicus. Plant Physiology 137, 1174-1181. doi: 10.1104/pp.104.057034

Manuscript received 5 April 2006, accepted 15 June 2006 